\title{
Promotoras as Mental Health Practitioners in Primary Care: A Multi-Method Study of an Intervention to Address Contextual Sources of Depression
}

\author{
Howard Waitzkin · Christina Getrich • Shirley Heying • Laura Rodríguez • \\ Anita Parmar $\cdot$ Cathleen Willging $\cdot$ Joel Yager $\cdot$ Richard Santos
}

Published online: 30 September 2010

(C) Springer Science+Business Media, LLC 2010

\begin{abstract}
We assessed the role of promotoras - briefly trained community health workers-in depression care at community health centers. The intervention focused on four contextual sources of depression in underserved, lowincome communities: underemployment, inadequate housing, food insecurity, and violence. A multi-method design included quantitative and ethnographic techniques to study predictors of depression and the intervention's impact. After
\end{abstract}

H. Waitzkin ( $\square)$

University of New Mexico, Albuquerque, NM 87131, USA

e-mail: waitzkin@unm.edu

C. Getrich

Department of Family and Community Medicine,

University of New Mexico, Albuquerque, NM, USA

C. Getrich $\cdot$ S. Heying $\cdot$ C. Willging

Department of Anthropology, University of New Mexico,

Albuquerque, NM, USA

L. Rodríguez

The Community Coalition for Healthcare Access,

Albuquerque, NM, USA

\section{A. Parmar}

The Robert Wood Johnson Foundation Center for Health Policy, University of New Mexico, Albuquerque, NM, USA

C. Willging

The Behavioral Health Research Center of the Southwest,

Albuquerque, NM, USA

J. Yager

Department of Psychiatry, University of Colorado,

Denver, CO, USA

R. Santos

Department of Economics, University of New Mexico,

Albuquerque, NM, USA a structured training program, primary care practitioners (PCPs) and promotoras collaboratively followed a clinical algorithm in which PCPs prescribed medications and/or arranged consultations by mental health professionals and promotoras addressed the contextual sources of depression. Based on an intake interview with 464 randomly recruited patients, 120 patients with depression were randomized to enhanced care plus the promotora contextual intervention, or to enhanced care alone. All four contextual problems emerged as strong predictors of depression (chi square, $p<.05$ ); logistic regression revealed housing and food insecurity as the most important predictors (odds ratios both $2.40, p<.05)$. Unexpected challenges arose in the intervention's implementation, involving infrastructure at the health centers, boundaries of the promotoras' roles, and "turf" issues with medical assistants. In the quantitative assessment, the intervention did not lead to statistically significant improvements in depression (odds ratio 4.33, confidence interval overlapping 1). Ethnographic research demonstrated a predominantly positive response to the intervention among stakeholders, including patients, promotoras, PCPs, non-professional staff workers, administrators, and community advisory board members. Due to continuing unmet mental health needs, we favor further assessment of innovative roles for community health workers.

Keywords Mental health - Health services accessibility . Primary health care - Community health aides .

Community health centers

\section{Introduction}

Substantial barriers to adequate services affect people with mental health problems [1]. When people seek mental 
health services, they tend to do so in the primary care sector $[2,3]$. However, primary care practitioners (PCPs) often do not recognize mental health disorders, do not provide adequate treatment, and report difficulties in responding to patients' psychosocial needs [1, 4-6].

We report here the results of an intervention in which promotoras (community health workers) assisted in the identification and treatment of depression within community health centers (CHCs). Our aims were: (1) to educate promotoras about depression; (2) to implement and evaluate a procedure for promotoras to identify depression among patients who sought primary care services; (3) to implement and evaluate a procedure by which patients identified with depression received treatment through the collaboration of promotoras and PCPs; and (4) to assess the value achieved by this intervention, as determined by outcome measures and as perceived by key stakeholders. The main research question, focusing on the fourth aim, asked: To what extent can an intervention that uses promotoras to address social contextual sources of depression achieve improved outcomes in patients and acceptance by stakeholders?

Our project focused specifically on efforts by promotoras to address four sources of depression in patients' social context: underemployment, inadequate housing, food insecurity, and violence. We used a multi-method research design, with quantitative methods to determine the predictors of depression and the impact of the intervention on outcomes, and ethnographic methods to assess the intervention's implementation and impact as perceived by key stakeholders. To our knowledge, our project was the first multi-method evaluation of promotoras focusing on depression among patients in primary care.

\section{Diagnosing and Improving Services for Depression in Primary Care}

\section{Screening for Mental Disorders and Intervention Trials}

When patients who present to primary care settings receive screening, the prevalence of depression generally ranges from 20 to $50 \%$. These prevalence rates vary considerably according to setting, method of assessment, language used, and race/ethnicity [7-12].

Intervention trials for psychiatric disorders in large primary care settings such as managed care organizations [1318] have included improved depression treatment by systems modification or quality improvement programs to foster evidence-based care [19-23]. In the Partners in Care study, guideline-informed interventions resulted in improved quality of care, quality of life, clinical outcomes, and employment retention; cost effectiveness analysis also showed substantial benefits [24-26]. Enhanced depression care for minorities has led to long-term improvements in outcomes [27]. Most intervention strategies include guideline-informed "best practices" for recognition and treatment of depression [28-32]. Recent intervention research demonstrates the value of enhanced, collaborative approaches [33-41]. Several studies substantiate the efficacy of collaborative interventions for depression in primary care for ethnically diverse and underserved populations [42-48]. Nevertheless, disparities remain in the care of patients treated in primary care settings, especially for minorities [49].

\section{Promotoras and the Challenges of Underserved Areas}

Promotoras have become a widely adopted work role in underserved communities [50,51]. Our definition of promotora refers to her or his role as a trusted community member, who provides health-related services for underserved individuals in community settings and helps fortify the relationship between patients and PCPs [52-55]. Community health workers are known by nearly 30 titles such as: promotoras de salud (Spanish for "health promoters"), community health advocates, outreach workers, indigenous health workers, lay health educators, and community health aides $[56,57]$.

Other than mental health services, promotoras have performed a variety of duties: first aid, nutrition education, blood pressure screenings, midwifery, translation, environmental work, patient transportation, case management, breast cancer screening, diabetes education, asthma management, social work, and peer counseling [58-61]. The Diabetes Initiative of the Robert Wood Johnson Foundation has included promotoras focusing in part on depression [62, 63]. Promotoras may help PCPs to identify patients' health needs and to consider the cultural relevance of treatments provided [64].

Researchers have assessed the efficacy of promotora interventions focusing on heart disease [65], diabetes [66], tobacco [67], general chronic diseases [68], breast and cervical cancer [69, 70], and nutrition [71]. These studies generally showed favorable intervention effects. Regarding applicability to diverse cultures and ethnicities, studies in Panama [72], Uganda [73], and Chile [74] showed positive results from training non-physicians for depression interventions in rural settings. A curriculum "toolbox" was developed for promotoras to use for English and Spanishspeaking diabetic patients with depression [75].

Public Health, Risk Factors for Mental Disorders, and Contextual Conditions

Efforts by NIMH, the Surgeon General, the World Health Organization, the President's New Freedom Commission on Mental Health, and the Institute of Medicine have 
emphasized interventions to impact risk factors for mental illness [76-79]. Social risk factors for depression include domestic violence, traumatic life events, marital discord, unmarried status, job stress, underemployment, poverty, and social isolation [80-84]. We documented the relationship of contextual problems, such as violence, to depression and other mental disorders among Latino and American Indian patients seen in primary care settings [85-87]. Long-term outcomes may improve through reducing social risk factors for stressful life events [88]. The "behavioral model for vulnerable populations" also has addressed some of these contextual influences on health outcomes, for example regarding issues of violence as well as financial, nutritional, and housing insecurity among homeless women [89-91].

Conceptual Framework, Objectives, and Significance

In recent research, social contextual conditions such as underemployment [92-97], inadequate housing [98-101], and food insecurity [102-109] figure as important risk factors in depression. Depression-causing violence, another risk factor, can arise in the family, between intimate partners, in child abuse, and or in the community [110-119].

Remarkably little research has examined the impact of interventions designed to modify such contextual difficulties, especially in primary care. In non-medical settings, experimental or quasi-experimental research has shown that contextual interventions directed toward underemployment [120-122], inadequate housing [123-126], domestic violence [127], and poverty [128] exerted favorable effects on mental health outcomes. From an extensive review, however, we located only one intervention trial that specifically addressed contextual problems in primary care. For a randomized urban trial, Miranda et al. compared group cognitive behavioral therapy (CBT) alone, versus CBT plus clinical care management. In the CBT plus clinical care management group, social work care managers addressed problems in housing, employment, recreation, and interpersonal relationships, which resulted in better mental health outcomes [129].

Figure 1 shows our conceptual framework. Adopting Engel's "biopsychosocial" approach [130, 131], we considered the importance of biological and psychological conditions in the etiology and treatment of depression. However, we also emphasized social conditions as causative elements in depression, recognizing that contextual conditions not only can affect depression but that depression can contribute to worsening social conditions, especially in such arenas as unemployment, housing insecurity, food insecurity, and violence. For that reason, we depicted the relationships between depression and contextual conditions as bidirectional.

\section{Methods}

Research Setting

At the time of the study, New Mexico ranked 47th among the 50 states in personal income per capita $(\$ 24,291)$ [132], 3 rd in persons below the poverty level $(18.4 \%)$ [133], 2nd in lack of health insurance (22.1\%) [134], and 1st to 11th in underemployment, reflecting the economy's volatility [135, 136]. Latinos and American Indians made up 51.6\% of the state's population [136]. The state's drug- and alcoholinduced death rates per population ranked 1 st and 2 nd highest respectively, the suicide death rate 5th highest, and the homicide death rate 6th highest in the United States [137].

\section{Recruitment of Promotoras and Educational Approach}

We initially hired two applicants: a receptionist at a CHC and a security guard. Both promotoras, bilingual in English and Spanish, were high school graduates with roots in the community. When 1 of the original promotoras left because of major health and financial problems, we recruited another promotora.

Five training sessions took place at each of the two participating CHCs. A prior mentorship program served as a model for the educational program [138]. Conferences for promotoras, $\mathrm{PCPs}$, and other staff members took place over the lunch hour at the CHCs. Promotoras also took part in an educational program on depression for community health workers.

\section{Assessment Instruments}

\section{Demographic Data}

An initial instrument assessed age, gender, income, employment status, socioeconomic status, marital status and children, immigration status, and number of years in the United States.

\section{Mental Health Disorders}

We used the extensively validated Patient Health Questionnaire (PHQ), whose 16 questions identified threshold DSM-IV diagnoses of major depressive disorder, panic disorder, other anxiety disorder, and bulimia nervosa, and subthreshold diagnoses (encompassing fewer symptoms than required for specific DSM-IV disorders) of other depressive disorder, probable alcohol abuse or dependence, somatoform disorder, and binge eating disorder [139-147]. We added a section assessing drug abuse or dependence, patterned on the PHQ alcohol section [148]. For Spanish- 
Fig. 1 Conceptual framework for the proposed research

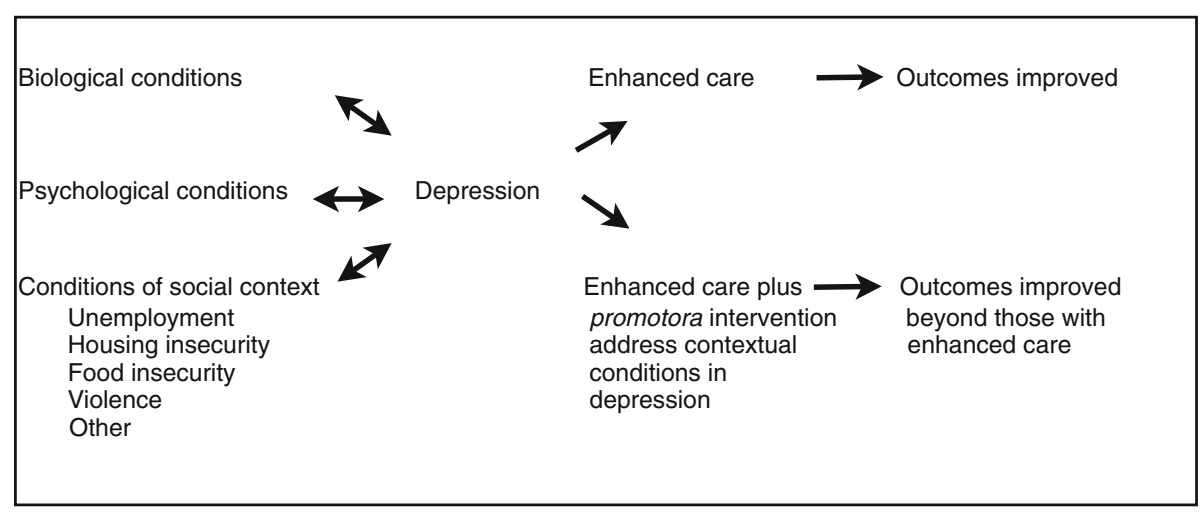

speaking patients, we used the Spanish version of the PHQ, previously validated in primary care settings $[149,150]$.

\section{Contextual Risk Factors}

Additional instruments elicited information about marital or partnership change, geographical relocation, job loss, job change, housing problems, and food insecurity. We used the Trauma Screening Questionnaire and StaT instruments to measure trauma exposure and intimate partner violence $[151,152]$.

\section{Pre-Test}

We pre-tested the PHQ instrument with 150 patients and then made limited modifications so the intake interview took less than $1 \mathrm{~h}$. No modifications in the Spanish PHQ proved necessary for the local setting.

\section{Promotora-PCP Consultation}

Before patients entered the study, we provided the PCPs with clinical guidelines on "best practice" diagnosis and treatment of depression [153]. The medications and frequency of recommended follow-up in the guidelines were modified slightly, based on medications available in the CHCs' formulary and practitioners' schedules. For each patient recruited, the PCP received the PHQ results from the promotora. The PCP did not receive reminders or inducements, with a rationale of restricting the experimental variable to the promotora-based algorithm described below.

\section{Subjects, Sample Size}

\section{Recruitment}

The promotoras recruited patients from the list of scheduled patients for each day, using a table of random numbers to determine which patients to approach for participation in the study. We randomized recruitment activities at the
CHCs by day of the week and by morning versus afternoon sessions. To ensure adequate follow-up, patients were informed at intake that they would be invited to participate in one or more follow-up interviews. Re-contact information was collected on all participants, including the names, addresses, and phone numbers of at least two other relatives or close friends who would know the subjects' whereabouts.

\section{Inclusion and Exclusion Criteria}

Patients were included if they met the criteria for a diagnosis of depression on the PHQ. The exclusion criteria were: (a) suicidal or homicidal ideation (emergency care was provided to such patients); (b) acute bereavement; (c) psychotic or bipolar depression; (d) age under 18; and (e) general health status precluding the interview.

\section{Sample Size Determination, Statistical Power}

In determining sample size, we made the following assumptions. The significance level was set at 0.05 and the desired statistical power at 0.80 . Based on prior interventions, we anticipated medium effect size $(0.3)$ for the intervention. We assumed conservatively a $10 \%$ prevalence of depression. With an anticipated attrition rate of $15 \%$, a sample size of 1,040 respondents would detect all relevant effects of the intervention [154-156]. Because the prevalence of depression observed in the study itself was higher, $28 \%$, we were able to reduce the total number of enrolled subjects from 1,040 to 464 . From the intake, we recruited 120 patients with depression.

\section{Intervention}

\section{Intervention Algorithm}

We developed an algorithm that the promotoras and PCPs applied collaboratively (Fig. 2). If the PHQ indicated a depression diagnosis, the promotoras provided this information to the PCP, who initiated treatment with medication 
At both $\mathrm{CHCs}$ (control and intervention sites)

PHQ leads to diagnosis of depression. promotora provides both raw responses to the individual $\mathrm{PHQ}$ items and a tallied PHQ score (plus a legend indicating how score range rates depression severity), clipped to the outside of the chart, waiting for the clinician to pick up just prior to seeing the patient.

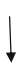

PCP confirms or disconfirms diagnosis through the depression guideline.

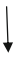

For patients with confirmed depression, PCP decides how to apply guideline for treatment with medications and/or counseling/ therapy.

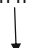

Promotoras retrieve all charts after the medical visit for those patients whose PHQ questionnaires are positive for "more than half the days" for questions $2 \mathrm{a}$ or $2 \mathrm{~b}$ and at least 1 other question $(2 \mathrm{c}-\mathrm{i})$, indicating at least moderate depression. Promotoras see which clinicians have made a diagnosis or treatment intervention.

PCP and promotora discuss plan:

1. Medication prescribed?

2. Referral for therapy?

3. When should promotora call patient to discuss status of depression medication compliance/side effects; questions patient has about prognosis/course? Promotora may note these in chart for provider to review with patient

4. When is next PCP-patient appointment?

5. Promotoraleaves contact form in chart.

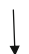

At intervention $\mathrm{CHC}$ only:

Promotorainterviews patient on contextual sources of depression (unemployment or under-employment, housing, food, trauma) using Factors Associated with Depression instrument.

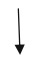

Promotorathen assists the patient to deal with the identified contextual sources of depression by mobilizing resources from the resource list and by providing other help at the promotora's discretion in relation to these problems only. Promotora documents activities in patient's chart.

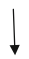

Promotora communicates at every 2 months with depressed patients at the intervention $\mathrm{CHCs}$ and reports findings by standard form to be placed in chart for PCP to review.

\section{At control and intervention CHCs:}

Promotora re-administers the PHQ (and other selected parts of the intake interview) at 6 months and 12 months after intake.

Fig. 2 Primary care practitioner-promotora algorithm

and/or arranged psychiatric or psychological consultation as warranted. The promotoras tried to address problems in four contextual areas: underemployment, inadequate housing, food insecurity, and violence. PCPs and promotoras communicated orally at least monthly. The algorithm also included follow-up PHQ assessments at 6 months and 12 months after diagnosis to determine changes in depression.

When the intake process revealed a contextual problem, the promotoras offered to seek a resolution. Promotoras used a resource directory that the CHC system had developed previously and which the research team updated and expanded. For instance, if a depressed patient reported a problem of unemployment or unstable employment, the promotora contacted one or more community based organizations that dealt with vocational training, rehabilitation, tracking jobs, advising about job interviews, and similar employment-related services. If a patient reported a problem of insecure housing or homelessness, the promotora helped contact organizations that focused on housing. For problems of food insecurity, the promotora facilitated contacts with churches, food banks, and government agencies that provided food stamps or helped clients obtain suitable foods. If a patient suffered from violence, the promotora helped seek assistance from shelters, programs focusing on abuse, etc. The promotora tracked the referral through monthly follow-up telephone calls with the patient and the organizations.

\section{Promotora Intervention Contact Form}

After each encounter with a patient, the promotoras wrote case notes and completed a form that specified the referrals and other actions taken to address contextual sources of depression that the patient reported.

\section{Intervention Implementation}

As in prior intervention trials such as the Partners in Care study, we randomized CHCs rather than patients within CHCs. We chose this approach to avoid the well documented problem of "contamination," which refers to an intervention's impact on control subjects at a clinical site [23-27].

Therefore, the algorithm was implemented at one "experimental" CHC in the network. At a "control" CHC, depression also was assessed by the PHQ and the findings were provided to PCPs, but the promotora algorithm was not implemented. At both $\mathrm{CHCs}$, depression care was enhanced through the education program described above. We determined which $\mathrm{CHC}$ received the promotora algorithm by a three out of five heads or tails coin flip. If the promotora intervention achieved positive outcomes at the experimental $\mathrm{CHC}$, the design called for its later implementation at the control CHC (Table 1).

\section{Quantitative Data Analysis}

\section{Predictors of Depression}

We first examined the univariate distributions of depression and other mental health disorders, risk factors, and 
Table 1 Research design for the promotora intervention

\begin{tabular}{lllllll}
\hline & $\begin{array}{l}\text { Intake interview } \\
\text { by promotoras }\end{array}$ & $\begin{array}{l}\text { PCP Dx } \\
\& \mathrm{Rx}\end{array}$ & $\begin{array}{l}\text { Promotora algorithm } \\
\text { (employment, housing, } \\
\text { food, violence) }\end{array}$ & $\begin{array}{l}\text { 6-month } \\
\text { assessment }\end{array}$ & $\begin{array}{l}\text { 12-month } \\
\text { assessment }\end{array}$ & $\begin{array}{l}\text { Promotora algorithm } \\
\text { (housing, food, } \\
\text { employment, violence) }\end{array}$ \\
\hline $\begin{array}{l}\text { Experimental CHC } \\
\text { Control CHC }\end{array}$ & $\mathrm{X}$ & $\mathrm{X}$ & $\mathrm{X}$ & $\mathrm{X}$ & $\mathrm{X}$ & $\mathrm{X}$ \\
$\mathrm{X}$ & $\mathrm{X}$ & $\mathrm{X}$ & $(\mathrm{X})$ \\
\hline
\end{tabular}

$P C P$ primary care practitioner, $D x$ diagnosis, $R x$ treatment

contextual problems. Depression was treated as a dichotomous dependent variable (present or absent), based on the standard PHQ scoring scheme. Independent variables included risk factors and contextual problems. Demographic characteristics and $\mathrm{CHC}$ site were intervening variables. Missing values for independent variables were imputed via a multiple imputation routine [157]. Multiple logistic regression determined the degree to which the independent variables predicted depression, controlling for intervening variables. We calculated odds ratios and $95 \%$ confidence intervals. Although not a standard use of the PHQ, we created a variable to indicate severity of depression by counting depressive symptoms and performed multiple regression analysis on this variable as well.

\section{Quantitative Assessment of the Intervention's Impact}

The unit of analysis was the individual patient. A two by two chi-square analysis assessed the effectiveness of the intervention for depression. Differences in other measures between the experimental and control $\mathrm{CHCs}$ were assessed with chi-square analyses (for nominal data) or multivariate analysis of variance (for interval data). We also assessed outcomes for patients served by each promotora through chi-square analyses. To determine the statistical significance of findings, we used two-tailed tests and a significance level of 0.05 .

Multivariate logistic regression models determined the relative importance of the intervention versus other key variables in predicting change in depression and other outcome indicators. Independent variables significantly associated with depression in the univariate and bivariate analyses were selected for the multivariate regression modeling procedures. For this analysis, improvement in depression was operationally defined as a transition from presence to absence, as assessed by the PHQ instrument.

To address non-independence of repeated observations for the same subjects, we used random effects in subjects and fixed effects in time [157]. Data were analyzed with SAS software (Cary, NC).
Ethnographic Assessment

\section{Participant Observation}

Four ethnographers completed more than $200 \mathrm{~h}$ of participant observation at the two CHC sites. The ethnographers "shadowed" the promotoras as they went about their workdays. We randomized observation periods by ethnographer, promotora observed, $\mathrm{CHC}$ site, day of the week, and time of day (morning or afternoon shift).

\section{Semi-Structured Interviews}

Interviews with stakeholders (patients, PCPs, and promotoras) permitted assessment of intervention implementation, barriers and facilitators that affected fidelity to the algorithm, and perceived value of the intervention. Interview guides followed a standardized structure, tailored to capture the experiences of each respondent group. The ethnographers interviewed the promotoras and a random selection of PCPs, patients, non-professional staff members, CHC administrators, and community board members. In all, the ethnographers conducted 35 semi-structured interviews.

\section{Ethnographic Data Analysis}

The ethnographers took extensive field notes and transcribed all interviews, inputting both sets of documents into NVivo [158], a software package for iterative coding and data analysis. They also reviewed the promotora intervention contact forms. Qualitative analysis identified common themes across and within respondent groups. Data were analyzed through iterative codings: "open coding" to uncover general themes, ideas, and issues; and "focused coding" to determine which of the themes, ideas, and issues were repeated often and which represented unusual or particular concerns [159].

To triangulate the data analysis, the ethnographers checked the consistency of information collected at different times and through different methods. This work compared observational data with medical chart data and 
interview data, checked for consistency in what respondents said about the intervention over time, and compared perspectives of the stakeholder groups [160].

\section{Results}

Identification, Correlates, and Predictors of Depression

Table $2 \mathrm{~A}$ presents the prevalences of depression and other mental health disorders at baseline. The PHQ instrument revealed depression in $28 \%$ of the patients screened. Somatoform disorders and anxiety disorders (including panic disorder) also occurred frequently, 16 and $17 \%$ respectively.

We used chi-square tests to examine associations between depression and demographic characteristics, contextual risk factors, and traumatic life events (Table 2BD). A higher proportion of non-US citizens was depressed, compared to US citizens (35 vs. 26\%). Subjects who experienced a recent move, job change, or job loss were much more likely to manifest depression. A much higher proportion of subjects who reported difficulties paying for housing or food was depressed. Depression was significantly more prevalent among subjects who had experienced traumatic life events, including general violence, intimate partner violence or threat, adult sexual violence, or childhood sexual violence.

With multiple logistic regression analysis, we examined the relative importance of demographic characteristics, contextual risk factors, and traumatic life events in predicting depression (Table 2E). From this analysis, significant predictors of depression included inadequate housing and food insecurity.

Implementation and Impact of the Intervention

\section{Quantitative Assessment of Outcomes}

Subjects in the experimental and control groups did not differ significantly by gender, marital status, marital status, employment, housing problems, food problems, or violence; subjects at the experimental site were slightly older and at the control site slightly more Hispanic in ethnicity (data not shown).

Chi-square analyses did not show a significant effect of the intervention on depression between baseline and 6 months, between baseline and 12 months, or between 6 and 12 months. In the multiple logistic regression analysis, which took into account the pertinent demographic and contextual variables, the intervention effect also did not reach significance in (Table 3). Multiple regression analysis using the measure of depression severity based on symptom count led to substantially similar results (data not shown).

We analyzed changes in the key contextual areas that the promotoras were to address in the intervention. At 12 months, the proportion of subjects with difficulty paying for housing decreased from 44 to $28 \%$ in the intervention group, and from 41 to $35 \%$ in the control groupnot a significant difference by Chi square. The proportion of unemployed remain about the same in the intervention group (47 vs. $45 \%$ ) but deteriorated in the control group (49 vs. $56 \%$ ), again not a significant difference.

No significant differences in the intervention's impact emerged when analyzed by promotora.

\section{Ethnographic Assessment of Intervention Implementation} and Outcomes

The ethnographic assessment revealed certain issues regarding fidelity of the implementation process [161]. First, some differences between the clinical sites became apparent. The randomly selected experimental site manifested space constraints, more staff turnover, and lower staff morale-all creating challenges for promotoras' work. The control site provided an office for the promotoras, maintained more continuity of staffing, and welcomed the promotoras more enthusiastically.

Confusion about the boundaries of promotoras' role affected the intervention's implementation. Promotoras became so closely associated with mental health that they received frequent requests to intervene in crises of patients who were not participating in the intervention. Staff members tried to refer additional patients to the promotoras, although the promotoras could not accept these referrals because of the random study design. Members of the research team met several times with staff members at both CHCs to clarify the limitations of the promotoras' training and responsibilities.

The roles of CHC staff members affected the algorithm's implementation. Medical assistants (MAs) unexpectedly became key players in the intervention. The MAs functioned as gatekeepers because they controlled the promotoras' access to medical files, exam rooms, and patients. Low-grade "turf wars" ensued in the initial phases at the experimental CHC site, where some MAs felt threatened by the promotoras. Due to this tension, the promotoras spent considerable time doing favors for the MAs, such as bringing patients into exam rooms, translating, or retrieving charts.

Regarding the intervention's impact, the ethnographic assessment revealed that key stakeholders perceived the intervention as a useful and cost-effective way to identify and treat depression. Patients, selected randomly to participate in the evaluation, conveyed a perception that the 
Table 2 Prevalence of mental disorders and predictors of depression

\begin{tabular}{|c|c|c|c|}
\hline Diagnosis & $\begin{array}{l}\text { Present } \\
N(\%)\end{array}$ & $\begin{array}{l}\text { Absent } \\
N(\%)\end{array}$ & $\begin{array}{l}\text { Total } \\
N^{\dagger}\end{array}$ \\
\hline \multicolumn{4}{|l|}{ A. Mental disorders } \\
\hline Major depression & $82(18)$ & $382(82)$ & 464 \\
\hline Other depression & $48(10)$ & $416(90)$ & 464 \\
\hline Panic disorder & $29(6)$ & $431(94)$ & 460 \\
\hline Other anxiety & $52(11)$ & $403(89)$ & 455 \\
\hline Alcohol disorder & $40(9)$ & $419(91)$ & 459 \\
\hline Somatoform disorder & $74(16)$ & $390(84)$ & 464 \\
\hline Bulimia nervosa & $4(1)$ & $453(99)$ & 457 \\
\hline \multirow[t]{2}{*}{ Binge eating disorder } & $12(3)$ & 445 (97) & 457 \\
\hline & $\begin{array}{l}\text { Depressed } \\
N(\%)\end{array}$ & $\begin{array}{l}\text { Not depressed } \\
N(\%)\end{array}$ & $\begin{array}{l}\text { Chi-square } \\
(p \text { value })\end{array}$ \\
\hline \multicolumn{4}{|c|}{ B. Demographic characteristics and depression } \\
\hline Gender & & & $(0.07)$ \\
\hline Male & $38(23)$ & $127(77)$ & \\
\hline Female & $92(31)$ & $207(69)$ & \\
\hline Marital status & & & $(0.25)$ \\
\hline Married & $53(25)$ & $156(75)$ & \\
\hline Not-married & $77(30)$ & $178(70)$ & \\
\hline Ethnicity & & & $(0.13)$ \\
\hline Hispanic & $118(29)$ & $284(71)$ & \\
\hline Non-Hispanic & $12(20)$ & $48(80)$ & \\
\hline Citizenship & & & $(0.05)$ \\
\hline US citizen & $79(26)$ & $226(74)$ & \\
\hline Non-US citizen & $49(35)$ & $92(65)$ & \\
\hline Age & & & $(0.04)$ \\
\hline Less than 30 years & $30(29)$ & $74(71)$ & \\
\hline Between 30 and 59 years & $85(31)$ & $187(69)$ & \\
\hline 60 years and over & $15(17)$ & $73(83)$ & \\
\hline \multicolumn{4}{|c|}{ C. Contextual risk factors and depression } \\
\hline Marital status change & & & $(0.18)$ \\
\hline Present & $17(36)$ & $30(64)$ & \\
\hline Absent & 107 (27) & $290(73)$ & \\
\hline Move & & & $(0.01)$ \\
\hline Present & $24(41)$ & $34(59)$ & \\
\hline Absent & $100(26)$ & $287(74)$ & \\
\hline Job change & & & $(0.02)$ \\
\hline Present & $39(37)$ & $66(63)$ & \\
\hline Absent & $85(25)$ & $255(75)$ & \\
\hline Job loss & & & $(0.001)$ \\
\hline Present & $35(43)$ & $46(57)$ & \\
\hline Absent & $89(25)$ & $273(75)$ & \\
\hline Housing problem & & & $(<.0001)$ \\
\hline Present & $52(56)$ & $41(44)$ & \\
\hline Absent & $71(20)$ & $280(80)$ & \\
\hline Food problem & & & $(<.0001)$ \\
\hline Present & $44(61)$ & $28(39)$ & \\
\hline Absent & $79(21)$ & $292(79)$ & \\
\hline Employment & & & $(0.91)$ \\
\hline Employed & $67(28)$ & $171(72)$ & \\
\hline Unemployed & $62(28)$ & $162(72)$ & \\
\hline
\end{tabular}


Table 2 continued

Depressed

Not depressed

Chi-square

$N(\%)$

$N(\%)$

( $p$ value)

D. Traumatic life events and depression

Major accident or disaster

(0.88)

Present

Absent

General violence

Present

Absent

Intimate partner violence/threat

Present

Absent

Adult sexual violence

Present

Absent

Childhood sexual violence

Present

Absent
28 (29)

93 (28)

29 (43)

91 (25)

44 (44)

76 (23)

15 (43)

105 (27)

20 (43)

98 (26)
70 (71)

242 (72)

38 (57)

274 (75)

20 (57)

255 (77)

20 (57)

289 (73)

26 (57)

283 (74)
(0.002)

(0.04)

(0.01)

\begin{tabular}{ll} 
Confidence interval $^{\dagger \dagger}$ & \\
\hline Lower bound & Upper bound
\end{tabular}

E. Logistic regression analysis for predictors of depression

Demographic characteristics

\begin{tabular}{|c|c|c|c|c|c|}
\hline Male & -0.32 & 0.26 & 0.73 & 0.43 & 1.22 \\
\hline Married $^{\mathrm{a}}$ & 0.00 & 0.25 & 1.00 & 0.61 & 1.65 \\
\hline Latino $^{\mathrm{b}}$ & 0.64 & 0.39 & 1.90 & 0.88 & 4.11 \\
\hline US citizen $^{\mathrm{c}}$ & -0.27 & 0.27 & 0.76 & 0.45 & 1.29 \\
\hline Age & 0.00 & 0.01 & 1.00 & 0.99 & 1.02 \\
\hline \multicolumn{6}{|l|}{ Contextual risk factors } \\
\hline Marital status change & -0.10 & 0.43 & 0.90 & 0.39 & 2.11 \\
\hline Move & 0.32 & 0.38 & 1.37 & 0.65 & 2.88 \\
\hline Job change & 0.19 & 0.33 & 1.20 & 0.63 & 2.32 \\
\hline Job loss & 0.29 & 0.36 & 1.33 & 0.66 & 2.72 \\
\hline Housing problem** & 0.88 & 0.33 & 2.40 & 1.26 & 4.58 \\
\hline Food problem* & 0.88 & 0.36 & 2.40 & 1.18 & 4.87 \\
\hline Employed $^{\mathrm{d}}$ & 0.12 & 0.25 & 1.12 & 0.69 & 1.84 \\
\hline \multicolumn{6}{|l|}{ Traumatic life event } \\
\hline Major accident or disaster & -0.16 & 0.30 & 0.85 & 0.47 & 1.54 \\
\hline General violence & 0.39 & 0.35 & 1.48 & 0.74 & 2.97 \\
\hline Intimate partner violence/threat & 0.60 & 0.33 & 1.83 & 0.97 & 3.46 \\
\hline Adult sexual violence & -0.22 & 0.48 & 0.80 & 0.31 & 2.05 \\
\hline Childhood sexual violence & 0.55 & 0.37 & 1.73 & 0.84 & 3.58 \\
\hline
\end{tabular}

$* p<.05$

$* * p<.01$

$\dagger$ Missing data are excluded

* B is the unstandardized regression coefficient

t† $95 \%$ confidence intervals are shown. $N=464$

${ }^{\text {a }}$ Reference category is not married

b Reference category is non-Latino

c Reference category is non-US citizen

d Reference category is unemployed 
Table 3 Logistic regression analysis for impact of intervention on depression ${ }^{\dagger}$

\begin{tabular}{|c|c|c|c|c|c|}
\hline & \multirow[t]{2}{*}{$\mathrm{B}^{*}$} & \multirow{2}{*}{$\begin{array}{l}\text { Standard } \\
\text { error of B }\end{array}$} & \multirow{2}{*}{$\begin{array}{l}\text { Odds } \\
\text { ratio }\end{array}$} & \multicolumn{2}{|c|}{ Confidence interval ${ }^{\dagger \dagger}$} \\
\hline & & & & Lower bound & Upper bound \\
\hline \multicolumn{6}{|l|}{ Intervention } \\
\hline Group $($ Intervention $=1)$ & 1.47 & 0.92 & 4.33 & 0.70 & 26.66 \\
\hline Time period $(12$ months $=1)$ & -0.71 & 0.70 & 0.49 & 0.12 & 1.94 \\
\hline Interaction: group $\times$ period & -1.27 & 0.92 & 0.28 & 0.05 & 1.73 \\
\hline \multicolumn{6}{|l|}{ Demographic characteristics } \\
\hline Male & 0.74 & 0.88 & 2.09 & 0.37 & 11.82 \\
\hline Married $^{\mathrm{a}}$ & 0.43 & 0.78 & 1.53 & 0.33 & 7.13 \\
\hline US citizen ${ }^{\mathrm{b}}$ & -0.36 & 0.76 & 0.70 & 0.16 & 3.14 \\
\hline Age & 0.05 & 0.03 & 1.05 & 0.99 & 1.11 \\
\hline \multicolumn{6}{|l|}{ Contextual risk factors } \\
\hline Job change & -0.70 & 0.99 & 0.50 & 0.07 & 3.47 \\
\hline Housing problem & 1.21 & 0.94 & 3.34 & 0.52 & 21.47 \\
\hline Food problem & -0.09 & 0.96 & 0.91 & 0.14 & 6.08 \\
\hline Employed $^{\mathrm{c}}$ & -1.21 & 0.71 & 0.30 & 0.07 & 1.22 \\
\hline \multicolumn{6}{|l|}{ Traumatic life event } \\
\hline Major accident or disaster & -0.29 & 0.90 & 0.75 & 0.13 & 4.39 \\
\hline General violence & 0.54 & 1.04 & 1.71 & 0.22 & 13.44 \\
\hline Intimate partner violence/threat & 1.26 & 0.94 & 3.52 & 0.54 & 22.70 \\
\hline Adult sexual violence & 0.61 & 1.10 & 1.84 & 0.21 & 16.29 \\
\hline Childhood sexual violence & 0.88 & 0.82 & 2.42 & 0.48 & 12.26 \\
\hline
\end{tabular}

$\dagger$ Missing data are excluded

* $\mathrm{B}$ is the unstandardized regression coefficient

${ }^{\dagger} 95 \%$ confidence intervals are shown. $N=165$

${ }^{a}$ Reference category is not married

${ }^{b}$ Reference category is non-US citizen

${ }^{c}$ Reference category is unemployed health services provided by promotoras. Community advisory board members approved an extension of the promotora model to additional CHCs in the network.

\section{Challenges and Opportunities}

An unexpected internal challenge involved turnover of clinical staff members, especially at the experimental $\mathrm{CHC}$ site. All six PCPs at the experimental $\mathrm{CHC}$ who received training about the intervention left the $\mathrm{CHC}$ during the project. This turnover reflected transitions in careers and/or family circumstances that did not relate to the intervention. Four new PCPs who joined the staff at the experimental $\mathrm{CHC}$ received individualized training from project team members. At the control CHC, four of the six PCPs remained throughout the project.

For two promotoras, the project provided opportunities for career advancement. One promotora re-entered college studies and eventually finished graduate school in social work. Another promotora continued working at a $\mathrm{CHC}$, supported by funding to expand behavioral health services.

On the other hand, one of the original promotoras left the project due to serious health and financial problems. Eventually he chose to work in the field of used car refurbishment-an occupation that he viewed as more financially lucrative. 
Ethnographic analysis of the intervention contact forms showed that the promotoras did identify contextual sources of depression in underemployment, inadequate housing, food insecurity, and violence and intervened appropriately in making referrals and providing other forms of assistance. However, patients of the promotora who experienced health and financial problems received these measures less promptly and less consistently than those followed by the promotora who remained throughout the project.

\section{Discussion}

Overview and Interpretation of Findings

Our research led to mixed findings. The project showed that the promotora model for depression care can achieve implementation at $\mathrm{CHCs}$ and can generate perceptions of value among a wide cross-section of stakeholders. Despite the favorable observations from the ethnographic evaluation, the quantitative assessment did not reveal a statistically significant impact of the promotora intervention on depression, the key targeted outcome.

Several issues may help explain the lack of significant impact in the quantitative assessment. First, as observed in the ethnographic research, sources of clinic "noise" impinged on the fidelity of the intervention's implementation. Unexpected differences between the clinical sites, including a more favorable environment at the control site, may have reduced the intervention's impact as assessed quantitatively. Because the promotoras' role remained unclear to some staff members, expectations exceeded the promotoras' training or job description. Finally, unpredicted "turf" conflicts arose between MAs and promotoras.

Secondly, due to serious illness and financial crisis, one promotora could not work with patients for approximately 5 months. After he eventually left the project, substantial delays occurred in hiring a suitable replacement.

Despite extensive re-contact information to assure adequate follow-up, subjects proved more mobile than expected. While the final number of subjects remained large enough to assure adequate statistical power, we remain uncertain if the lack of statistically significant differences reflected issues of fidelity and discontinuity, rather than an ineffective intervention.

Policy Implications

The CHC network followed federal guidelines for integrating behavioral health services within the primary care setting [78]. After this project, the CHC network modified the guidelines to include a promotora as a team member.
The promotora's activities focused on access, contextual problems, and sources of non-adherence.

Negotiations continued between the CHC network and third-party payers for reimbursement of promotora services. This process proved partly successful, as one of the 3 for-profit managed care organizations contracting under Medicaid agreed to reimburse specified mental health services offered by promotoras. Later, a major behavioral health initiative of state government included a role for promotoras as service providers, and the state's Department of Health organized an office focusing on community health workers in primary care and mental health. Such policy changes may provide a precedent for consideration in other geographical areas.

\section{Implications for Research}

To assist in policy decisions regarding promotora services, we argue for additional research that addresses some issues that we clarified in this study. Such research should take place on a scale large enough and with enough attention to variations in clinical settings to permit more definitive conclusions about the efficacy of promotoras as fullfledged members of clinical teams.

Differences in initial CHC environments should receive attention in interventions with promotoras or similar community health workers. Selection of clinical sites should consider differences in history and institutional culture. Although budgetary considerations influenced our decision to compare only two $\mathrm{CHCs}$, we now recognize the importance of randomizing an intervention like this one to a larger number of intervention and control $\mathrm{CHCs}$, to address variability among clinical sites.

Research in CHCs should anticipate constraints of clinical staffing. Non-PCP and non-promotora staff members should take part in planning research activities. Predictable turnover of PCPs and promotoras should receive attention in planning. For instance, we might have identified the problems experienced by one promotora earlier and addressed them more effectively. Despite budgetary limitations, we probably should have have employed more than two promotoras to reduce the likelihood that unanticipated difficulties experienced by one promotora would hinder the intervention and its assessment.

\section{Conclusion}

This project aimed to assess the role of promotoras in depression care at primary care clinics. Despite unexpected challenges, the promotoras achieved wide acceptance and support among stakeholders such as patients, PCPs, and administrators. The ethnographic assessment reached 
mainly favorable conclusions about the role of promotoras and the value of their work in addressing contextual sources of depression. Nevertheless, the quantitative assessment did not confirm the intervention's favorable impact on depression outcomes.

We remain uncertain about the future role of promotoras in depression care. Due to the differences that emerged from the ethnographic and quantitative assessments, the lack of significant quantitative findings to demonstrate the intervention's efficacy becomes less convincing than it otherwise might. Overall, the research effort revealed some of the vicissitudes of implementing and evaluating an intervention that addresses an important problem and that seems on face value to be a good idea.

Given the dire gaps in services that persist in underserved inner cities and rural areas, we favor a further assessment of innovative roles for new mental health practitioners who are firmly rooted in their communities. In such efforts, the sources of depression in contextual problems like underemployment, inadequate housing, food insecurity, and violence-whose importance as predictors of depression this study confirmed-warrant more attention than they have received so far.

Acknowledgments This project was funded in part by the Robert Wood Johnson Foundation (grant 048127). The Robert Wood Johnson Foundation Center for Health Policy at the University of New Mexico provided additional support for statistical analyses. We thank the rest of the research team (Maureen Kelly, Margaret Menache, Jesse Méndez, D. Imelda Padilla-Frausto, Linda Pérez, and Aki Roberts). Christopher Lyons provided expert statistical consultation. Most importantly, we express our gratitude to the patients, practitioners, staff members, and community advisory board members who participated in the study.

\section{References}

1. Kessler, R., Demler, O., Frank, R., et al. (2005). Prevalence and treatment of mental disorders, 1990 to 2003. New England Journal of Medicine, 352(24), 2515-2523.

2. National Institute of Mental Health. (2010). Strategic plan. Retrieved August 23, 2010 at http://www.nimh.nih.gov/about/ strategic-planning-reports/index.shtml.

3. Wang, P. S., Lane, M., Olfson, M., et al. (2005). Twelve-month use of mental health services in the United States: Results from the National Comorbidity Survey Replication. Archives of General Psychiatry, 62(6), 629-640.

4. Borowsky, S. J., Rubenstein, L. V., Meredith, L. S., et al. (2000). Who is at risk of nondetection of mental health problems in primary care? Journal of General Internal Medicine, 15(6), 381-388.

5. Holman, E. A., Silver, R. C., \& Waitzkin, H. (2000). Traumatic life events in primary care patients: A study in an ethnically diverse sample. Archives of Family Medicine, 9(9), 802-810.

6. Rizzo, V. M., Mizrahi, T., \& Kirkland, K. (2005). Psychosocial problems among patients in neighborhood health centers: Perspectives from health care providers. Journal of Community Health, 30(2), 125-140.
7. Gallo, J. J., Bogner, H. R., Morales, K. H., et al. (2005). Patient ethnicity and the identification and active management of depression in late life. Archives of Internal Medicine, 165(17), 1962-1968.

8. Hansson, M., Chotai, J., Nordstom, A., et al. (2009). Comparison of two self-rating scales to detect depression: HADS and PHQ-9. British Journal of General Practice, 59(566), 650-654.

9. Hauenstein, E. J., \& Peddada, S. (2007). Prevalence of major depressive episodes in rural women using primary care. Journal of Health Care for the Poor and Underserved, 18(1), 185-202.

10. Mitchell, A. J., Vaze, A., \& Rao, S. (2009). Clinical diagnosis of depression in primary care: A meta-analysis. Lancet, 374(9690), 609-619.

11. Reuland, D. S., Cherrington, A., Watkins, G. S., et al. (2009). Diagnostic accuracy of Spanish language depression-screening instruments. Annals of Family Medicine, 7(5), 455-462.

12. Schmaling, K. B., \& Hernandez, D. V. (2005). Detection of depression among low-income Mexican Americans in primary care. Journal of Health Care for the Poor and Undeserved, 16(4), 780-790.

13. Fleming, M. F., Barry, K. L., Manwell, L. B., et al. (1997). Brief physician advice for problem alcohol drinkers: A randomized controlled trial in community-based primary care practices. JAMA, 277(13), 1039-1045.

14. Fleming, M. F., Mundt, M. P., French, M. T., et al. (2000). Benefit-cost analysis of brief physician advice with problem drinkers in primary care settings. Medical Care, 38(1), 7-18.

15. Harvey, I., Nelson, S. J., Lyons, R. A., et al. (1998). A randomized controlled trial and economic evaluation of counselling in primary care. British Journal of General Practice, 48(428), 1043-1048.

16. Rollman, B. L., Hanusa, B. H., Gilbert, T., et al. (2001). The electronic medical record. A randomized trial of its impact on primary care physicians' initial management of major depression [corrected]. Archives of Internal Medicine, 161(2), 189-197.

17. Simon, G. E., VonKorff, M., Heiligenstein, J. H., et al. (1996). Initial antidepressant choice in primary care: Effectiveness and cost of fluoxetine vs tricyclic antidepressants. JAMA, 275(24), 1897-1902.

18. Williams, J. W., Barrett, J., Oxman, T., et al. (2000). Treatment of dysthymia and minor depression in primary care: A randomized controlled trial in older adults. JAMA, 284(12), $1519-1526$.

19. Katon, W., Von Korff, M., Lin, E., et al. (1999). Stepped collaborative care for primary care patients with persistent symptoms of depression: A randomized trial. Archives of General Psychiatry, 56(12), 1109-1115.

20. Rost, K., Nutting, P., Smith, J., et al. (2001). Improving depression outcomes in community primary care practice: A randomized trial of the QuEST intervention. Journal of General Internal Medicine, 16(3), 143-149.

21. Rubenstein, L. V., Jackson-Triche, M., Unutzer, J., et al. (1999). Evidence-based care for depression in managed primary care practices. Health Affairs, 18(5), 89-105.

22. Unutzer, J., Rubenstein, L., Katon, W. J., et al. (2001). Two-year effects of quality improvement programs on medication management for depression. Archives of General Psychiatry, 58(10), 935-942.

23. Wells, K. B., Sherbourne, C., Schoenbaum, M., et al. (2000). Impact of disseminating quality improvement programs for depression in managed primary care: A randomized controlled trial. JAMA, 283(2), 212-220.

24. Schoenbaum, M., Unutzer, J., Sherbourne, C., et al. (2001). Cost-effectiveness of practice-initiated quality improvement for depression: Results of a randomized controlled trial. JAMA, 286(11), 1325-1330. 
25. Sherbourne, C. D., Weiss, R., Duan, N., et al. (2004). Do the effects of quality improvement for depression care differ for men and women? Results of a group-level randomized controlled trial. Medical Care, 42(12), 1186-1193.

26. Wells, K. B., Schoenbaum, M., Duan, N., et al. (2007). Costeffectiveness of quality improvement programs for patients with subthreshold depression or depressive disorder. Psychiatric Services, 58(10), 1269-1278.

27. Wells, K. B., Sherbourne, C. D., Miranda, J., et al. (2007). The cumulative effects of quality improvement for depression on outcome disparities over 9 years: Results from a randomized, controlled group-level trial. Medical Care, 45(11), 1052-1059.

28. Clarke, G. N. (1995). Improving the transition from basic efficacy research to effectiveness studies: Methodological issues and procedures. Journal of Consulting and Clinical Psychology, 63(5), 718-725.

29. Dietrich, A. J., Oxman, T. E., Williams, J. W., et al. (2004). Reengineering systems for the treatment of depression in primary care: Cluster randomised controlled trial. British Medical Journal, 329(7466), 602-605.

30. Essock, S. M., Goldman, H. H., Anthony, W. A., et al. (2003). Evidence-based practices: Setting the context and responding to concerns. Psychiatric Clinics of North America, 26(4), 919.

31. Gray, G. E., \& Pinson, L. A. (2003). Evidence-based medicine and psychiatric practice. Psychiatric Quarterly, 74(4), 387-399.

32. Klinkman, M. S. (2003). The role of algorithms in the detection and treatment of depression in primary care. Journal of Clinical Psychiatry, 64, 19-23.

33. Bruce, M. L., Ten Have, T. R., Reynolds, C. F., et al. (2004). Reducing suicidal ideation and depressive symptoms in depressed older primary care patients: A randomized controlled trial. JAMA, 291(9), 1081-1091.

34. Craven, M. A., \& Bland, R. (2006). Better practices in collaborative mental health care: An analysis of the evidence base. Canadian Journal of Psychiatry, 51(6 Suppl 1), 7S-72S.

35. Hegel, M. T., Unutzer, J., Tang, L. Q., et al. (2005). Impact of comorbid panic and posttraumatic stress disorder on outcomes of collaborative care for late-life depression in primary care. American Journal of Geriatric Psychiatry, 13(1), 48-58.

36. Hunkeler, E. M., Katon, W., Tang, L., et al. (2006). Long-term outcomes from the IMPACT randomised trial for depressed elderly patients in primary care. British Medical Journal, 332(7536), 259-263.

37. Katon, W., Unutzer, J., Fan, M. Y., et al. (2006). Cost-effectiveness and net benefit of enhanced treatment of depression for older adults with diabetes and depression. Diabetes Care, 29(2), 265-270.

38. Nutting, P. A., Gallagber, K., Riley, K., et al. (2008). Care management for depression in primary care practice: Findings from the RESPECT-depression trial. Annals of Family Medicine, 6(1), 30-37.

39. Nutting, P. A., Gallagher, K. M., Riley, K., et al. (2007). Implementing a depression improvement intervention in five health care organizations: Experience from the RESPECTdepression trial. Administration and Policy in Mental Health and Mental Health Services Research, 34(2), 127-137.

40. Oxman, T. E., Schulberg, H. C., Greenberg, R. L., et al. (2006). A fidelity measure for integrated management of depression in primary care. Medical Care, 44(11), 1030-1037.

41. Williams, J. W., Katon, W., Lin, E. H. B., et al. (2004). The effectiveness of depression care management on diabetes-related outcomes in older patients. Annals of Internal Medicine, 140(12), 1015-1024.

42. Ayalon, L., Arean, P. A., Linkins, K., et al. (2007). Integration of mental health services into primary care overcomes ethnic disparities in access to mental health services between black and white elderly. American Journal of Geriatric Psychiatry, 15(10), 906-912.

43. Cooper, L. A., Gonzales, J. J., Gallo, J. J., et al. (2003). The acceptability of treatment for depression among AfricanAmerican, Hispanic, and white primary care patients. Medical Care, 41(4), 479-489.

44. Miranda, J., Bernal, G., Lau, A., et al. (2005). State of the science on psychosocial interventions for ethnic minorities. Annual Review of Clinical Psychology, 1, 113-142.

45. Miranda, J., Chung, J. Y., Green, B. L., et al. (2003). Treating depression in predominantly low-income young minority women: A randomized controlled trial. JAMA, 290(1), 57-65.

46. Miranda, J., Duan, N. H., Sherbourne, C., et al. (2003). Improving care for minorities: Can quality improvement interventions improve care and outcomes for depressed minorities? Results of a randomized, controlled trial. Health Services Research, 38(2), 613-630.

47. Rojas, G., Fritsch, R., Solis, J., et al. (2007). Treatment of postnatal depression in low-income mothers in primary-care clinics in Santiago, Chile: A randomised controlled trial. Lancet, 370(9599), 1629-1637.

48. Wells, K., Sherbourne, C., Schoenbaum, M., et al. (2004). Fiveyear impact of quality improvement for depression: Results of a group-level randomized controlled trial. Archives of General Psychiatry, 61(4), 378-386.

49. Stockdale, S. E., Lagomasino, I. T., Siddique, J., et al. (2008). Racial and ethnic disparities in detection and treatment of depression and anxiety among psychiatric and primary health care visits, 1995-2005. Medical Care, 46(7), 668-677.

50. Ramos, I. N., May, M., \& Ramos, K. S. (2001). Environmental health training of promotoras in colonias along the TexasMexico border. American Journal of Public Health, 91(4), 568-570.

51. Williams, D. M. (2001). La promotora: Linking disenfranchised residents along the border to the U.S. healthcare system. Health Affairs, 20(3), 212-218.

52. Hanscom, K. L. (2001). Treating survivors of war trauma and torture. American Psychologist, 56(11), 1032-1039.

53. McElmurry, B. J., Park, C. G., \& Buseh, A. G. (2003). The nursecommunity health advocate team for urban immigrant primary health care. Journal of Nursing Scholarship, 35(3), 275-281.

54. Nemcek, M. A., \& Sabatier, R. (2003). State of evaluation: Community health workers. Public Health Nursing, 20(4), 260-270.

55. Zuvekas, A., Nolan, L., Tumaylle, C., et al. (1999). Impact of community health workers on access, use of services, and patient knowledge and behavior. Journal of Ambulatory Care Management, 22(4), 33-44.

56. Balcázar, H., Alvarado, M., Cantu, F., et al. (2009). A promotora de salud model for addressing cardiovascular disease risk factors in the US-Mexico border region. Preventing Chronic Disease, 6(1), A02.

57. Rodríguez, V. M., Conway, T. L., Woodruff, S. I., et al. (2003). Pilot test of an assessment instrument for Latina community health advisors conducting an ETS intervention. Journal of Immigrant and Minority Health, 5(3), 129-137.

58. Berg, J., Anderson, N. L., Tichacek, M. J., et al. (2007). One gets so afraid: Latino families and asthma management: An exploratory study. Journal of Pediatric Health Care, 21, 361-371.

59. Joshu, C. E., Rangel, L., Garcia, O., et al. (2007). Integration of a promotora-led self-management program into a system of care. Diabetes Educator, 33, 151S-158S.

60. Lujan, J., Ostwald, S. K., \& Ortiz, M. (2007). Promotora diabetes interventions for Mexican Americans. Diabetes Education, $33(4), 660-670$. 
61. Sauaia, A., Min, S. J., Lack, D., et al. (2007). Church-based breast cancer screening education: impact of two approaches on Latinas enrolled in public and private health insurance plans. Preventing Chronic Disease, 4(4), A99.

62. Anderson, D., O'Toole, M. L., Brownson, C. A., et al. (2007). Integrating depression care with diabetes care in real-world settings: Lessons from the Robert Wood Johnson Foundation Diabetes Initiative. Diabetes Spectrum, 20(1), 10-16.

63. Robert Wood Foundation. (2006). The diabetes initiative of the robert wood foundation. Retrieved August 23, 2010 from http://rwjf.org/files/research/diabetesinitiativeoverview.pdf.

64. Center for Disease Control and Prevention. (2010). Community health workers/promotores de salud: Critical connections in communities. Retrieved August 23, 2010 from http://www.cdc. gov/diabetes/projects/comm.htm.

65. Balcázar, H., Alvarado, M., Hollen, M. L., et al. (2006). Salud para su corazón-NCLR: A comprehensive promotora outreach program to promote heart-healthy behaviors among hispanics. Health Promotion Practice, 7(1), 68-77.

66. Teufel-Shone, N. I., Drummond, R., \& Rawiel, U. (2005). Developing and adapting a family-based diabetes program at the US-Mexico border. Preventing Chronic Disease, 2(1), A20.

67. Conway, T. L., Woodruff, S. I., Edwards, C. C., et al. (2004). Intervention to reduce environmental tobacco smoke exposure in Latino children: Null effects on hair biomarkers and parent reports. Tobacco Control, 13(1), 90-92.

68. Hunter, J. B., de Zapien, J. G., Papenfuss, M., et al. (2004). The impact of a promotora on increasing routine chronic disease prevention among women aged 40 and older at the US-Mexico border. Health Education Behavior, 31(4 Suppl), 18S-28S.

69. Hansen, L. K., Feigl, P., Modiano, M. R., et al. (2005). An educational program to increase cervical and breast cancer screening in Hispanic women: A southwest oncology group study. Cancer Nursing, 28(1), 47-53.

70. Welsh, A. L., Sauaia, A., Jacobellis, J., et al. (2005). The effect of two church-based interventions on breast cancer screening rates among Medicaid-insured Latinas. Preventing Chronic Disease, 2(4).

71. Elder, J. P., Ayala, G. X., Campbell, N. R., et al. (2005). Interpersonal and print nutrition communication for a Spanishdominant Latino population: Secretos de la buena vida. Health Psychology, 24(1), 49-57.

72. Moreno, P., Saravanan, Y., Levav, I., et al. (2003). Evaluation of the PAHO/WHO training program on the detection and treatment of depression for primary care nurses in Panama. Acta Psychiatrica Scandinavica, 108(1), 61-65.

73. Bolton, P., Bass, J., Neugebauer, R., et al. (2003). Group interpersonal psychotherapy for depression in rural Uganda: A randomized controlled trial. JAMA, 289(23), 3117-3124.

74. Araya, R., Rojas, G., Fritsch, R., et al. (2003). Treating depression in primary care in low-income women in Santiago, Chile: A randomised controlled trial. Lancet, 361(9362), 995-1000.

75. Reinschmidt, K. M. \& Chong, J. (2007). SONRISA: A curriculum toolbox for promotores to address mental health and diabetes. Preventing Chronic Disease, 4(4): A101. Electronic publication September 15.

76. Committee on the Future of Rural Health Care. (2004). Quality through collaboration: The future of rural health care. Washington, DC: National Academy of Sciences.

77. President's New Freedom Commission on Mental Health. (2003). Achieving the promise: Transforming mental health care in America. Final Report. Rockville, MD: Department of Health and Human Services.

78. U.S. Health Resources and Service Administration. Mental health. Retrieved August 23, 2010 from http://www.hrsa.gov/ mentalhealth/default.htm.
79. World Health Organization. (2001). Mental health: New understanding, new hope. World health report. Geneva: World Health Organization.

80. Brown, G. W. (1997). A psychosocial perspective and the aetiology of depression. In A. Honig \& H. M. van Praag (Eds.), Depression: Neurobiological, psychopathological \& therapeutic advances. New York: Wiley.

81. Brown, G. W., \& Moran, P. (1994). Clinical and psychosocial origins of chronic depressive episodes I: A community survey. British Journal of Psychiatry, 165, 447-456.

82. Brown, G. W., \& Moran, P. M. (1997). Single mothers, poverty and depression. Psychological Medicine, 27(1), 21-33.

83. Eaton, W. W., Muntaner, C., Bovasso, G., et al. (2001). Socioeconomic status and depressive syndrome: The role of inter- and intra-generational mobility, government assistance, and work environment. Journal of Health and Social Behavior, 42(3), 277-294.

84. Tiwari, A., Chan, K. L., Fong, D., et al. (2008). The impact of psychological abuse by an intimate partner on the mental health of pregnant women. BJOG, 115(3), 377-384.

85. Duran, B., Malcoe, L. H., Sanders, M., et al. (2004). Child maltreatment prevalence and mental disorders outcomes among American Indian women in primary care. Child Abuse and Neglect, 28(2), 131-145.

86. Duran, B., Sanders, M., Skipper, B., et al. (2004). Prevalence and correlates of mental disorders among native American women in primary care. American Journal of Public Health, 94(1), 71-77.

87. Escobar, J. I., Waitzkin, H., Silver, R. C., et al. (1998). Abridged somatization: A study in primary care. Psychosomatic Medicine, 60(4), 466-472.

88. Sherbourne, C. D., Edelen, M. O., Zhou, A., et al. (2008). How a therapy-based quality improvement intervention for depression affected life events and psychological well-being over time: A 9-year longitudinal analysis. Medical Care, 46(1), 78-84.

89. Austin, E. L., Andersen, R., \& Gelberg, L. (2008). Ethnic differences in the correlates of mental distress among homeless women. Women's Health Issues, 18(1), 26-34.

90. Gelberg, L., Andersen, R. M., \& Leake, B. D. (2000). The behavioral model for vulnerable populations: Application to medical care use and outcomes for homeless people. Health Services Research, 34(6), 1273-1302.

91. Stein, J. A., Andersen, R., \& Gelberg, L. (2007). Applying the Gelberg-Andersen behavioral model for vulnerable populations to health services utilization in homeless women. Journal of Health Psychology, 12(5), 791-804.

92. Ansseau, M., Fischler, B., Dierick, M., et al. (2008). Socioeconomic correlates of generalized anxiety disorder and major depression in primary care: The GADIS II study (Generalized Anxiety and Depression Impact Survey II). Depression and Anxiety, 25(6), 506-513.

93. Fortney, J., Rushton, G., Wood, S., et al. (2007). Communitylevel risk factors for depression hospitalizations. Administration and Policy in Mental Health and Mental Health Services Research, 34(4), 343-352.

94. Gallo, W. T., Bradley, E. H., Dubin, J. A., et al. (2006). The persistence of depressive symptoms in older workers who experience involuntary job loss: Results from the health and retirement survey. Journals of Gerontology Social Sciences, 61(4), S221-S228.

95. Gilchrist, G., \& Gunn, J. (2007). Observational studies of depression in primary care: What do we know? BioMed Family Practice, 8(28), 93.

96. Mascaro, N., Arnette, N. C., Santana, M. C., et al. (2007). Longitudinal relations between employment and depressive symptoms in low-income, suicidal African American women. Journal of Clinical Psychology, 63(6), 541-553. 
97. Stack, S., \& Wasserman, I. (2007). Economic strain and suicide risk: A qualitative analysis. Suicide and Life-Threatening Behavior, 37(1), 103-112.

98. Fone, D., Dunstan, F., Williams, G., et al. (2007). Places, people and mental health: a multilevel analysis of economic inactivity. Social Science and Medicine, 64(3), 633-645.

99. Galea, S., Ahern, J., Rudenstine, S., et al. (2005). Urban built environment and depression: A multilevel analysis. Journal of Epidemiology and Community Health, 59(10), 822-827.

100. Karim, K., Tischler, V., Gregory, P., et al. (2006). Homeless children and parents: Short-term mental health outcome. International Journal of Social Psychiatry, 52(5), 447-458.

101. Siefer, K., Finalayson, T. L., Williams, D. R., et al. (2007). Modifiable risk and protective factors for depressive symptoms in low-income African American mothers. American Journal of Orthopsychiatry, 77(1), 113-123.

102. Alegría, M., Pérez, D. J., \& Williams, S. (2003). The role of public policies in reducing mental health status disparities for people of color. Health Affairs (Milwood), 22(5), 51-64.

103. Casey, P., Goolsby, S., Berkowitz, C., et al. (2004). Maternal depression, changing public assistance, food security, and child health status. Pediatrics, 113(2), 298-304.

104. Chilton, M., \& Booth, S. (2007). Hunger of the body and hunger of the mind: African American women's perceptions of food insecurity, health and violence. Journal of Nutrition, Education and Behavior, 39(3), 116-125.

105. Huddleston-Casas, C., Charnigo, R., \& Simmons, L. A. (2009). Food insecurity and maternal depression in rural, low-income families: A longitudinal investigation. Public Health Nutrition, 12(8), 1133-1140.

106. Kim, K., \& Frongillo, E. A. (2007). Participation in food assistance programs modifies the relation of food insecurity with weight and depression in elders. Journal of Nutrition, 137(4), $1005-1010$.

107. Siefert, K., Heflin, C. M., Corcoran, M. E., et al. (2004). Food insufficiency and physical and mental health in a longitudinal survey of welfare recipients. Journal of Health and Social Behavior, 45(2), 171-186.

108. Weigel, M. M., Armijos, R. X., Hall, Y. P., et al. (2007). The household food insecurity and health outcomes of U.S.-Mexico border migrant and seasonal farmworkers. Journal of Immigrant and Minority Health, 9(3), 157-169.

109. Whitaker, R. C., Phillips, S. M., \& Orzol, S. M. (2006). Food insecurity and the risks of depression and anxiety in mothers and behavior problems in their preschool-aged children. Pediatrics, 118(3), e859-e868.

110. Clark, C., Ryan, L., Kawachi, I., et al. (2008). Witnessing community violence in residential neighborhoods: A mental health hazard for urban women. Journal of Urban Health Bulletin of the New York Academy of Medicine, 85(1), 22-38.

111. Coker, A. L., Smith, P. H., \& Fadden, M. K. (2005). Intimate partner violence and disabilities among women attending family practice clinics. Journal of Women's Health, 14(9), 829-838.

112. Dervic, K., Grunebaum, M. F., Burke, A. K., et al. (2006). Protective factors against suicidal behavior in depressed adults reporting childhood abuse. Journal of Nervous and Mental Disease, 194(12), 971-974.

113. Fedovskiy, K., Higgins, S., \& Paranjape, A. (2008). Intimate partner violence: How does it impact major depressive disorder and post traumatic stress disorder among immigrant Latinas? Journal of Immigrant and Minority Health, 10(1), 45-51.

114. Fogarty, C. T., Fredman, L., Heeren, T. C., et al. (2008). Synergistic effects of child abuse and intimate partner violence on depressive symptoms in women. Preventive Medicine, 46(5), $463-469$.
115. Geiger-Brown, J., Muntaner, C., McPhaul, K., et al. (2007). Abuse and violence during home care work as predictor of worker depression. Home Health Care Services Quarterly, 26(1), 59-77.

116. Goldstein, A. L., Walton, M. A., Cunningham, R. M., et al. (2007). Violence and substance use as risk factors for depressive symptoms among adolescents in an urban emergency department. Journal of Adolescent Health, 40(3), 276-279.

117. Hicks, M. H. R., \& Li, Z. H. (2003). Partner violence and major depression in women: A community study of Chinese Americans. Journal of Nervous and Mental Disease, 191(11), 722-729.

118. Koopman, C., Ismailji, T., Palesh, O., et al. (2007). Relationships of depression to child and adult abuse and bodily pain among women who have experienced intimate partner violence. Journal of Interpersonal Violence, 22(4), 438-455.

119. Storr, C. L., Ialongo, N. S., Anthony, J. C., et al. (2007). Childhood antecedents of exposure to traumatic events and posttraumatic stress disorder. American Journal of Psychiatry, 164(1), 119-125.

120. Matt, G. E., Bellardita, L., Fischerand, G., et al. (2006). Psychological resources and mental health among the difficult to employ: Can a pre-employment training program make a difference? Journal of Vocational Rehabilitation, 24(1), 33-43.

121. Vinokur, A. D., Schul, Y., Vuori, J., et al. (2000). Two years after a job loss: Long-term impact of he JOBS program on reemployment and mental health. Journal of Occupational Health Psychology, 5(1), 32-47.

122. Vuori, J., \& Silvonen, J. (2005). The benefits of a preventive job search program on re-employment and mental health at two-year follow-up. Journal of Occupational \& Organizational Psychology, 78, 43-52.

123. Fauth, R. C., Leventhal, T., \& Brooks-Gunn, J. (2004). Shortterm effects of moving from public housing in poor to middleclass neighborhoods on low-income, minority adults' outcomes. Social Science and Medicine, 59(11), 2271-2284.

124. Katz, L. F., Kling, J. R., \& Liebman, J. B. (2001). Moving to opportunity in Boston: Early results of a randomized mobility experiment. Quarterly Journal of Economics, 116(2), 607-654.

125. Kling, J. R., Liebman, J. B., \& Katz, L. F. (2007). Experimental analysis of neighborhood effects. Econometrica, 75(1), 83-119.

126. Leventhal, T., \& Brooks-Gunn, J. (2003). Moving to opportunity: An experimental study of neighborhood effects on mental health. American Journal of Public Health, 93(9), 1576-1582.

127. Sullivan, C. M., Bybee, D. I., \& Allen, N. E. (2002). Findings from a community-based program for battered women and their children. Journal of Interpersonal Violence, 17(9), 915-936.

128. Gassman-Pines, A., \& Yoshikawa, H. (2006). Five-year effects of an anti-poverty program on marriage among never-married mothers. Journal of Policy Analysis and Management, 25(1), $11-30$.

129. Miranda, J., Azocar, F., Organista, K. C., et al. (2003). Treatment of depression among impoverished primary care patients from ethnic minority groups. Psychiatric Services, 54(2), 219-225.

130. Borrell-Carrio, F., Suchman, A. L., \& Epstein, R. M. (2004). The biopsychosocial model 25 years later: Principles, practice, and scientific inquiry. Annals of Family Medicine, 2(6), $576-582$.

131. Engel, G. L. (1977). Need for a new medical model: Challenge for biomedicine. Science, 196(4286), 129-136.

132. U.S. Census Bureau. (2008). Statistical abstract of the United States: 2005. Personal income per capita in constant in dollars, 2007. Retrieved August 23, 2010 from http://www.census.gov/ statab/ranks/rank34.html. 
133. U. S. Bureau. (2005). Statistical abstract of the United States: 2005. Persons below poverty level. Washington, DC: Government Printing Office.

134. U. S. Census Bureau. (2005). Statistical abstract of the United States: 2005. Washington, DC: Government Printing Office.

135. U. S. Census Bureau. (1999). Statistical abstract of the United States: 1999. Washington, DC: Government Printing Office.

136. U. S. Census Bureau. (2005). Statistical abstract of the United States: 2006. Washington, DC: Government Printing Office.

137. Morgan, K. O., \& Morgan, S. (2007). Health care state rankings 2005: Health care in the 50 United States. Lawrence, KS: Morgan Quitno Press.

138. Waitzkin, H., Yager, J., Parker, T., \& Duran, B. (2006). Mentoring partnerships for minority faculty and graduate students in mental health services research. Academic Psychiatry, 30(3), 205-217.

139. Brody, D. S., Hahn, S. R., Spitzer, R. L., et al. (1998). Identifying patients with depression in the primary care setting: A more efficient method. Archives of Internal Medicine, 158(22), 2469-2475.

140. Connelly, J. E., Wofford, A. B., \& Philbrick, J. T. (2000). Healthy patients who perceive poor health: Why are they worried sick? American Journal of the Medical Sciences, 320(1), $36-42$.

141. Hahn, S. R. (2001). Physical symptoms and physician-experienced difficulty in the physician-patient relationship. Annals of Internal Medicine, 134(9), 897-904.

142. Jackson, J. L., Houston, J. S., Hanling, S. R., et al. (2001). Clinical predictors of mental disorders among medical outpatients. Archives of Internal Medicine, 161(6), 875-879.

143. Lefevre, F., Reifler, D., Lee, P., et al. (1999). Screening for undetected mental disorders in high utilizers of primary care services. Journal of General Internal Medicine, 14(7), 425-431.

144. Miranda, J., Azocar, F., Komaromy, M., et al. (1998). Unmet mental health needs of women in public-sector gynecologic clinics. American Journal of Obstetrics and Gynecology, 178(2), 212-217.

145. Schriger, D. L., Gibbons, P. S., Langone, C. A., et al. (2001). Enabling the diagnosis of occult psychiatric illness in the emergency department: A randomized, controlled trial of the computerized, self-administered PRIME-MD diagnostic system. Annals of Emergency Medicine, 37(2), 132-140.

146. Spitzer, R. L., Williams, J. B., Kroenke, K., et al. (2000). Validity and utility of the PRIME-MD Patient Health Questionnaire in assessment of 3000 obstetric-gynecologic patients: The PRIME-MD Patient Health Questionnaire Obstetrics
Gynecology Study. American Journal of Obstetrics and Gynecology, 183(3), 759-769.

147. Thompson, M. A., Unützer, J., Katon, W. J., et al. (1999). Detection and treatment of depressive syndromes in a rural island clinic. Journal of the American Board of Family Medicine, 12(2), 120-127.

148. Olfson, M., Shea, S., Feder, A., et al. (2000). Prevalence of anxiety, depression, and substance use disorders in an urban general medicine practice. Archives of Family Medicine, 9(9), 876-883.

149. Baca, E., Saiz, J., Aguera, L., et al. (1999). Validation of the Spanish version of PRIME-MD: A procedure for diagnosing mental disorders in primary care. Actas Espanolas De Psiquiatria, 27(6), 375-381.

150. Baca-Baldomero, E., Sáiz-Ruiz, J., Agüera-Ortiz, L. F., et al. (1999). Prevalencia de los trastornos psiquiátricos en atención primaria usando el cuestionario PRIME-MD. Actas Españolas de Psiquiatría, 27(6), 375-383.

151. McIntyre, L. M., Butterfield, M. I., Nanda, K., et al. (1999). Validation of a trauma questionnaire in veteran women. Journal of General Internal Medicine, 14(3), 186-189.

152. Paranjape, A., \& Liebschutz, J. (2003). STAT: A three-question screen for intimate partner violence. Journal of Women's Health and Gender-Based Medicine, 12(3), 233-239.

153. Agency for Healthcare Research and Quality. (2009). The treatment and management of depression in adults. Retrieved August 23, 2010 from http://www.guideline.gov/content. aspx $?$ id $=15521 \&$ search=depression.

154. Cohen, J. (1988). Statistical power analysis for the behavioral sciences (2nd ed.). Hillsdale, NJ: L. Erlbaum Associates.

155. Hinlus, J. (2001). NCCS-PASS. Kaysville, UT: NCSS Statistical Software.

156. Peduzzi, P., Concato, J., Kemper, E., et al. (1996). A simulation study of the number of events per variable in logistic regression analysis. Journal of Clinical Epidemiology, 49(12), 1373-1379.

157. Menard, S. (2001). Applied logistic regression analysis. Thousand Oaks, CA: Sage.

158. QSR International. (2010). NVivo 8. Retrieved August 23, 2010 from http://www.qsrinternational.com.

159. Emerson, R. M., Fretz, R. I., \& Shaw, L. L. (1995). Writing ethnographic fieldnotes. Chicago: University of Chicago Press.

160. Patton, M. Q. (1999). Enhancing the quality and credibility of qualitative analysis. Health Services Research, 34(5), 1189-1208.

161. Getrich, C., Heying, S., Willging, C., et al. (2007). An ethnography of clinic "noise' in a community-based, promotora-centered mental health intervention. Social Science and Medicine, 65(2), 319-330. 